960

EVALUATION OF A NEW INDIRECT BLOOD PRESSURE SYSTEM FOR NEONATES. Leonard L. Fox, Dale L. Phelps, (Spon. Dept. of Pediatrics, Los Angeles, California.

Infrasonde ${ }^{R}$ (Sphyngometrics), a small, lightweight (6.2 1bs), battery-powered, indirect blood pressure system was tested under a variety of clinical conditions in neonates. This system consists of a passive transducer $(1 \times 1 \mathrm{~cm})$ placed under a disposable cuff which electronlcally senses arterial wall oscillations on a narrow subaudible (infrasonic) frequency band thereby improving accuracy by increasing the signal to noise ratio.

Ten neonates ( 1360 to $4500 \mathrm{gms}$ ), catheterfzed for medical reasons (RDS, shock, sepsis), were studied. Approximately 20 readings each by experienced and inexperienced personnel were made on the right arm, left arm, and one leg, simultaneously recording the direct transducer pressure from an arterial catheter attached to a KDC monitor at the exact moment that the Infrasonde reading was taken. Comparing absolute differences between the Infrasonde and the direct arterial pressure over a wide range (diastolic 18 to $60 \mathrm{~mm} \mathrm{Hg}$, systolic 38 to $105 \mathrm{~mm} \mathrm{Hg}$ ), were unable to detect any difference between experienced and inexperienced personnel, right and left arms, and arms and legs; therefore all the readings were combined. The correlation co-
efficient between direct artertal and Infrasonde pressures was $r=.900, n=113$ diastolic and $r=.940, n=113$ systolic.

These data indicate that Infrasonde correlates well with direct arterial pressures and could be especially useful when there is no indwelling catheter present.

961

EFFECTS OF INTRALIPID INFUSIONS ON ARTERIAL BLOOD GASES AND PULMONARY FUNCTION IN SMALL PREMATURE NEO-
NATES. WIIllam W. FOX, Gilberto $R$ P NATES. William W. Fox, Gilberto R. Pereira, Jacob G. Schwartz. (Spon. by Jean A. Cortner), Univ. of Pa. Sch. of Med. Dept. of Peds. and The Children's Hosp. of Phila., Phila., PA.
. Pal

Intralipid is widely used for parenteral nutrition of infants with respiratory distress but hypoxemia has been reported in adults receiving IV intralipld infusions. To determine changes in pulmonary function during a $4 \mathrm{hr}$. intralipid infusion, $1 \mathrm{gm} / \mathrm{kg}$
intralipid was administered to $7 \mathrm{small}$ premature neonates with mean wt. $1.16 \mathrm{~kg}$ (range $0.88-1.50$ ) and mean gest. age 29 weeks. Arterial blood gases, func. resid. cap. (FRC), tidal volume (TV), resp. rate $(R R)$, lung compliance $\left(C_{L}\right)$ and insp. $\left(R_{I}\right)$ and exp. $\left(R_{E}\right)$ pulmonary resistance, serum triglycerides (TG) and exp. ty acids (FFA) were determined at control (pre-infusion), at 4 hours and at followup ( 4 hours after infusion). Control (mean SEM) FFA $(0.58 \pm .17)$ and TG $(54.1 \pm 6.3)$ increased at 4 hours to $2.0 \pm 0.37$ and $230.0 \pm 66.2$. Control P02 $(66.4+11.1)$ decreased post infusion to $54.1 \pm 2.1 \mathrm{~mm} \mathrm{Hg}$. At followup, both mean FFA and TG were higher than control values and less than post infusion. Mean \pm SEM followup P02 $(62.6+6.4)$ was higher than post infusion but lower than controls. There were no significant differences in pC02, pH, base excess, RR, VT, min. vent., CL, R $R_{E}$, or FRC for all 3 parts of the study. This study indicates that intralipid infusion in premature neonates affects $\mathrm{PO}_{2}$ but does not cause quantitative changes in other blood gas parameters or pulmonary function.

962 BICARBONLATE (B) AND INITRACRAIIAL MIMIOPRHAGE (ICH) IN HYALINE MERIBRANE DISEASE (HND). Zvi Friedman, Curtis
A. Cammarata, Keith H. Marks, M. Jeffrey Maisels. Penn State Univ Coll Med, M S Hershey Med Ctr, Dept Ped, Ilershey, PA.

We studied the relationship between $B$ administration and ICH in 53 infants with $\mathrm{HMD} .27$ had no ICH (Group I). 26 had ICH of whom 10 received $B$ prior to the diagnosis of ICH (Group IIa) and 16 received $B$ after ICH was diagnosed (Group IIb).

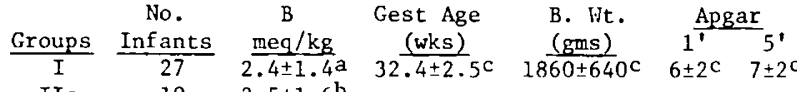

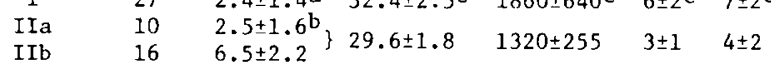

$$
\begin{aligned}
& \text { a - Group I vs IIb } p<0.01 \\
& \text { b - Group IIa vs IIb p < } 0.01 \\
& \text { c - Group I vs IIa }+ \text { b p }<0.01
\end{aligned}
$$

There were no significant differences between the groups in the level of serum sodium, osmolality, inborn/outborn ratio and age of admission to NICU.

We conclude that a direct relationship exists between ICH, perinatal asphyxia and prematurity. No correlation was found between $B$ administration and $\mathrm{ICH}$.

Harvard Medical School, Boston, MA.

In an attempt to correlate the thymolytic effect of glucocorticoids with their role in the induction of surfactant synthesis and the prevention of RDS, the size of the thymus on the initial chest radiographs of newborns who required intensive care was reviewed. Utilizing a ratio of the cardiothymic silhouette at the carina to the thoracic width $(C-T / T)$ we found an increase in $\mathrm{C}-\mathrm{T} / \mathrm{T}$ with increasing gestational age. Newborn infants with RDS had a significantly elevated mean $\mathrm{C}-\mathrm{T} / \mathrm{T} \quad(0.40$ vs $0.36 ; \mathrm{p}<0.001)$ an increased percentage of 'enlarged' $(C-T / T>0.45)$ thymuses ( 288 vs 88 in non-RDS babies), and a decreased percentage of - small. (C-T/T 20.30 ) thyms , and a decreased percentage of small $(C-T / T<0.30)$ thymuses (118 vs. 268). Moreover, in a series of 8 multiple gestations that were discordant for RDS, the larger thymus was seen in those with RDS in 6 of 8 , while in only one did the converse hold true. Surprjsingly, babies whose mothers had received prepartum dexamethasone to prevent RDS showed no difference in thymic size when compared to a control population. These data are consistent with the theory that endogenous glucocorticoids play a physiologic role in the prevention of RDS. The initial size of the thymus may also be of predictive value in differentiating between the diverse causes of respiratory distress in newborn infants.

\title{
964 FETAL PROLACTIN (PRL) AND THE RESPIRATORY DISTRESS
} Kitterman, S.L. K.D. Gluckman, P.L. Ballard, J.A.
Kan, and M.M. Grumbach. Dept. Pediat., Univ. of California San Francisco, San Francisco, Ca. There is a temporal relationship between plasma PRL, cortisol (F) and pulmonary surfactant production in the fetus. PRL administered to fetal rabbits is reported to increase pulmonary surfactant content. To explore these relationships we have measured PRL in umbilical cord sera from 78 infants of gestational age 28 to 40 weeks. A positive relationship to gestational age was demonstrated. Between 30 and 36 weeks gestation, analysis of covariance of PRL versus gestational age showed that infants who did not develop RDS had significantly higher cord PRL concentrations ( $p<0.05)$ than infants who developed RDS. Between 32 and 35.5
weeks the mean \pm SEM cord PRL of normal infants (161.8 $18.9 \mathrm{ng} /$ $\mathrm{ml})$ is higher $(\mathrm{p}<0.025)$ than in those who developed RDS (101.7 \pm $9.5 \mathrm{ng} / \mathrm{m} 1)$. Growth hormone concentrations in the same samples dic not show any relationship to the incidence of RDS. Cord PRL did not correlate with cord F or dehydroeplandrosterone sulphate (DHEAS) concentration. Serum PRL was not suppressed in a second group of 114 infants whose mothers were treated prenatally with betamethasone, but F and DHEAS were. The finding of low cord PRL in infants who develop RDS is consistent with the possibility that PRL may influence fetal lung maturation.

To exclude the possibility that this potential association is due to a postulated adrenocorticotropic effect of PRL, we infused ovine PRL ( $1 \mathrm{mg} /$ day) into fetal sheep for periods of 6 to 8 days ovine PRL ( $\mathrm{mg} / \mathrm{day}$ ) into fetal sheep for periods of 6 to 8 days
in late gestation. No effect on F, DHEAS, or F binding capacity

965 PNEUMOPERICARDIUM: AN APPROACH TO DIAGNOSIS AND TREATMENT IN THE NEONATE. Ronald N. Goldberg, Luis A.
Cabal, Bijan Siassi and Joan E. Hodgman. Children's Hospital of Los AngeTes \& Univ. of So. CaTif. Sch. of Med., LACHSC Medical Center, Dept. of Pediatrics.
usc

Pneumopericardium (PPC) developed in 16 of $873(2 \%)$ neonates receiving assisted ventilation; 14 were prematures with RDS requiring assisted ventilation within 12 hours. Pneumothorax (PNX) developed coincidentally in all but one. Pericardiocentes is (PCX) was performed in 11 of whom $7(42 \%)$ survived. Cardiovascular parameters of heart rate (HR), arterial blood pressure (ABP) central venous pressure (CVP) and ECG were measured during 10 episodes of PPC. Early evidence of cardiac tamponade (CT) was moderate tachycardia and a sharp rise in CVP. This was followed by bradycardia and an abrupt decrease in pulse and ABP. Marked ST. segment depression with AV dissociation and $2^{\circ}$ heart block were noted at this time. Following PCX, a rebound tachycardia, widening of pulse pressure, return of ABP to basel ine and a gradual fall in CVP occurred in survivors while in those who died, bradycardia and hypotension persisted. PPC as a complication of assiscardia and hypotension persisted. PPC as a complication of assis-
ted ventilation should be expected in a small number of infants ted ventilation should be expected in a small number of infants
with RDS. If the infant develops a pneumothorax, this risk is with RDS. If the infant develops a pneumothorax, this risk is
significantly increased. The diagnosis can be made befcre death by cardiovascular changes described. The condition can be sucessfuily treated and adequacy of treatment can be assessed by the same factors used for diagnosis. 